\title{
Susceptibility of Well-Differentiated Airway Epithelial Cell Cultures from Domestic and Wild Animals to Severe Acute Respiratory Syndrome Coronavirus 2
}

Mitra Gultom, Matthias Licheri, Laura Laloli, Manon Wider, Marina Strässle, Philip V'kovski, ${ }^{1}$ Silvio Steiner, Annika Kratzel, Tran Thi Nhu Thao, Lukas Probst, Hanspeter Stalder, Jasmine Portmann, Melle Holwerda,

Nadine Ebert, Nadine Stokar-Regenscheit, Corinne Gurtner, Patrik Zanolari, Horst Posthaus,

Simone Schuller, Amanda Vicente-Santos, Andres Moreira-Soto, Eugenia Corrales-Aguilar, Nicolas Ruggli, Gergely Tekes, Veronika von Messling, Bevan Sawatsky, Volker Thiel, Ronald Dijkman

Severe acute respiratory syndrome coronavirus 2 (SARS-CoV-2) has spread globally, and the number of worldwide cases continues to rise. The zoonotic origins of SARS-CoV-2 and its intermediate and potential spillback host reservoirs, besides humans, remain largely unknown. Because of ethical and experimental constraints and more important, to reduce and refine animal experimentation, we used our repository of welldifferentiated airway epithelial cell (AEC) cultures from various domesticated and wildlife animal species to

$\mathrm{D}$ uring the past 2 decades we have observed zoonotic outbreaks of severe acute respiratory syndrome coronavirus (SARS-CoV) in 2003 and Middle East respiratory syndrome coronavirus (MERS-CoV) in $2012(1,2)$. These outbreaks have been followed by

Author affiliations: Institute for Infectious Diseases, University of Bern, Bern, Switzerland (M. Gultom, M. Licheri, L. Laloli, M. Wider, M. Strässle, L. Probst, M. Holwerda, R. Dijkman); University of Bern Department of Infectious Diseases and Pathobiology, Bern (M. Gultom, L. Laloli, M. Strässle, P. V'kovski, S. Steiner, A. Kratzel, T.T.N. Thao, H. Stalder, J. Portmann, M. Holwerda, N. Ebert, N. Stokar-Regenscheit, C. Gurtner, H. Posthaus, V. Thiel, R. Dijkman); Institute of Virology and Immunology, Bern and Mittelhäusern, Switzerland (M. Gultom, L. Laloli, M. Strässle, P. V'kovski, S. Steiner, A. Kratzel, T.T.N. Thao, H. Stalder, J. Portmann, M. Holwerda, N. Ebert, V. Thiel, R. Dijkman); University of Bern Graduate School for Biomedical Science, Bern (M. Gultom, L. Laloli, S. Steiner, A. Kratzel, T.T.N. Thao, L. Probst, M. Holwerda); Institute of Veterinary Bacteriology, University of Bern, Bern (M. Strässle); Institute of Animal Pathology, University of Bern, Bern assess their susceptibility to SARS-CoV-2. We observed that SARS-CoV-2 replicated efficiently only in monkey and cat AEC culture models. Whole-genome sequencing of progeny viruses revealed no obvious signs of nucleotide transitions required for SARS-CoV-2 to productively infect monkey and cat AEC cultures. Our findings, together with previous reports of human-to-animal spillover events, warrant close surveillance to determine the potential role of cats, monkeys, and closely related species as spillback reservoirs for SARS-CoV-2.

the current pandemic caused by the 2019 zoonotic emergence of severe acute respiratory syndrome coronavirus 2 (SARS-CoV-2), the etiologic agent of coronavirus disease (COVID-19) (3,4). Humans are currently seen as the main hosts, but the zoonotic

(N. Stokar-Regenscheit, C. Gurtner, H. Posthaus); Clinic for Ruminants, Vetsuisse Faculty, University of Bern, Bern (P. Zanolari); University of Bern Department of Clinical Veterinary Medicine, Bern (S. Schuller); Virology-Research Center for tropical diseases (CIET), University of Costa Rica, Montes de Oca, Costa Rica (A. Vicente-Santos, A. Moreira-Soto, E. Corrales-Aguilar); Institute of Virology, Charité-Universitätsmedizin Berlin, Corporate Member of Freie Universität Berlin, Humboldt-Universität zu Berlin, and Berlin Institute of Health, Berlin, Germany (A. Moreira-Soto); Institute of Virology, Justus Liebig University Giessen, Giessen, Germany (G. Tekes); Federal Institute for Vaccines and Biomedicines, Langen, Germany (V. von Messling, B. Sawatsky)

DOI: https://doi.org/10.3201/eid2707.204660

${ }^{1}$ Current affiliation: Institute for Infectious Diseases, University of Bern, Bern, Switzerland. 
origins and intermediate and potential spillback host reservoirs of SARS-CoV-2 are not yet well defined. Several reports indicate that SARS-CoV-2 spillover events from human to other animal species can occur (5-7). These zoonotic events are likely driven by close human-animal interactions and the conservation of crucial receptor binding motif (RBM) residues in the angiotensin-converting enzyme 2 (ACE2) orthologs, potentially facilitating SARS-CoV-2 entry $(8,9)$. This knowledge gap highlights the need to assess the potential host spectrum for SARS-CoV-2 to support current pandemic mitigation strategies.

Besides their use in determining the host spectrum, animal models will be needed for viral pathogenesis studies, as well as for testing novel antiviral drugs, immunotherapies, and vaccines against SARSCoV-2. Typically, in such studies a large variety of animal species are tested for susceptibility (10-12). However, such experiments have several drawbacks, including the availability of diverse animal models and the need for dedicated personnel, housing facilities, and most important, ethics approval. Some of these factors are especially limiting when applied to wildlife and livestock animals, such as pigs, cattle, and other ruminants; when working with companion animals and nonhuman primates, there are additional socioemotional and ethical considerations.

In this study, we evaluated the susceptibility of several mammal species to SARS-CoV-2 by recapitulating the initial stages of infection in a controlled in vitro model, in compliance with the reduction, refinement, and replacement principles in animal experimentation, while at the same time circumventing traditional in vivo experimental constraints. We used a unique well-differentiated airway epithelial cell (AEC) culture repository from the primary tracheobronchial airway tissue of 12 mammal species comprising companion animals, animal model candidates, livestock, and wild animals to assess their susceptibility to SARS-CoV-2 infection. To control for the quality of the AEC, we used influenza viruses that have known broad host tropism (13-15).

\section{Materials and Methods}

\section{Conventional Cell Culture}

We cultured Vero E6 cells in Dulbecco Modified Eagle medium supplemented with $10 \%$ volume/volume percent (vol/vol) heat-inactivated fetal bovine serum, $1 \mathrm{mmol} /$ L sodium pyruvate, $1 \times$ GlutaMAX, $100 \mu \mathrm{g} / \mathrm{mL}$ streptomycin, $100 \mathrm{IU} / \mathrm{mL}$ penicillin, $1 \% \mathrm{vol} / \mathrm{vol}$ nonessential amino acids, and $15 \mathrm{mmol} / \mathrm{L}$ HEPES buffering agent (GIBCO; https://www.thermofisher.com).
We maintained cells at $37^{\circ} \mathrm{C}$ in a humidified incubator with $5 \% \mathrm{CO}_{2}$.

\section{Establishment of Animal AEC Culture Repository}

We isolated tracheobronchial epithelial cells from 12 different animal species from postmortem tracheobronchial tissue that was obtained from slaughterhouses, veterinary hospitals, or domestic or international research institutes that euthanize their animals for diagnostic purposes or as part of their licensed experimental work in accordance with local regulations and ethics guidelines. We isolated and cultured the cells as described elsewhere (16). To establish welldifferentiated AEC cultures from diverse mammal species, we introduced several modifications to the composition of the air-liquid interface (ALI) medium (Table 1). We maintained all animal ALI cultures at $37^{\circ} \mathrm{C}$ in a humidified incubator with $5 \% \mathrm{CO}_{2}$. While the differentiated ALI cultures were developing over 3-4 wk, we changed media every 2-3 d.

\section{Virus Propagation}

We propagated SARS-CoV-2 (SARS-CoV-2/München$1.1 / 2020 / 929)$ virus stock in Vero E6 cells for $48 \mathrm{~h}$ then cleared virus-containing supernatant from cell debris by centrifuging for $5 \mathrm{~min}$ at $500 \times \mathrm{g}$ before aliquoting and storing it at $-80^{\circ} \mathrm{C}$. We determined viral titer by plaque forming unit (PFU) assay on Vero E6 cells as described elsewhere (17). We prepared working stocks of influenza A virus (IAV) A/Hamburg/4/2009 strain in the pHW2000 reverse genetic backbone by propagating the rescued virus in MDCK-II cells for $72 \mathrm{~h}$ in the infection medium, which was composed of Eagle Minimum Essential Medium, supplemented with $0.5 \%$ of bovine serum albumin, $100 \mu \mathrm{g} / \mathrm{mL}$ streptomycin and $100 \mathrm{IU} / \mathrm{mL}$ penicillin solution, $1 \mu \mathrm{g} / \mathrm{mL}$ trypsin acetylated from bovine pancreas (Sigma-Aldrich, https://www.sigmaaldrich.com), and $15 \mathrm{mmol} / \mathrm{L}$ HEPES buffer. We determined viral titer by $50 \%$ tissue culture infective dose $\left(\mathrm{TCID}_{50}\right)$ assay on MDCK-II cells as described elsewhere $(18,19)$. We propagated influenza D virus (IDV, D/bovine/Oklahoma/660/2013 strain) stocks in the human rectal tumor cell line HRT-18G (ATCC [American Type Culture Collection] CRL11663, https:/ / www.atcc.org) for $96 \mathrm{~h}$ in the infection medium, with the adjustment of using $0.25 \mu \mathrm{g} /$ $\mathrm{mL}$ of trypsin. We determined viral titer by $\mathrm{TCID}_{50}$ assay on HRT-18G cells as described elsewhere (20).

\section{Infection of Animal AEC Cultures}

We infected well-differentiated AEC cultures from 12 different species with 30.000 PFU of SARS-CoV-2, or $10.000 \mathrm{TCID}_{50}$ of either IAV or IDV, as described 
Table. Optimized epidermal growth factor, retinoic acid, hydrocortisone, and DAPT concentration in the air-liquid interface medium for differentiation of the animal airway epithelial cell cultures*

\begin{tabular}{|c|c|c|c|c|c|c|}
\hline \multirow[b]{2}{*}{ Animal species } & \multirow{2}{*}{$\begin{array}{l}\text { No. } \\
\text { donors }\end{array}$} & \multirow[b]{2}{*}{ Source } & \multicolumn{4}{|c|}{ End concentration additives in ALI medium } \\
\hline & & & EGF & RA & $\mathrm{HC}$ & DAPT \\
\hline Monkey (Rhesus macaque) & 2 & $\begin{array}{l}\text { Paul-Ehrlich-Institut, Langen, } \\
\text { Germany }\end{array}$ & $5 \mathrm{ng} / \mathrm{mL}$ & $50 \mathrm{nM}$ & $0.48 \mu \mathrm{g} / \mathrm{mL}$ & NS \\
\hline Ferret (Mustela putorius furo) & 2 & $\begin{array}{l}\text { Paul-Ehrlich-Institut, } \\
\text { Langen, Germany }\end{array}$ & $12.5 \mathrm{ng} / \mathrm{mL}$ & $100 \mathrm{nM}$ & $0.48 \mu \mathrm{g} / \mathrm{mL}$ & $2.5 \mu \mathrm{M}$ \\
\hline Cat (Felis catus) & 2 & $\begin{array}{l}\text { Justus-Liebig-University, Giessen, } \\
\text { Germany }\end{array}$ & $25 \mathrm{ng} / \mathrm{mL}$ & $50 \mathrm{nM}$ & $0.072 \mu \mathrm{g} / \mathrm{mL}$ & NS \\
\hline Dog (Canis lupus familiaris) & 1 & $\begin{array}{c}\text { Institute of Animal Pathology, } \\
\text { Bern, Switzerland }\end{array}$ & $25 \mathrm{ng} / \mathrm{mL}$ & $50 \mathrm{nM}$ & $0.072 \mu \mathrm{g} / \mathrm{mL}$ & NS \\
\hline Rabbit (Oryctolagus cuniculus) & 1 & $\begin{array}{c}\text { Slaughterhouse, Bern, } \\
\text { Switzerland }\end{array}$ & $25 \mathrm{ng} / \mathrm{mL}$ & $50 \mathrm{nM}$ & $0.48 \mu \mathrm{g} / \mathrm{mL}$ & NS \\
\hline Pig (Sus scrofa domesticus) & 2 & $\begin{array}{l}\text { Institute of Virology and } \\
\text { Immunology, Mittelhäusern, } \\
\text { Switzerland }\end{array}$ & $25 \mathrm{ng} / \mathrm{mL}$ & $70 \mathrm{nM}$ & $0.072 \mu \mathrm{g} / \mathrm{mL}$ & NS \\
\hline Cattle (Bos taurus) & 1 & $\begin{array}{l}\text { Institute of Animal Pathology, } \\
\text { University of Bern, Switzerland }\end{array}$ & $25 \mathrm{ng} / \mathrm{mL}$ & $50 \mathrm{nM}$ & $0.48 \mu \mathrm{g} / \mathrm{mL}$ & $2.5 \mu \mathrm{M}$ \\
\hline Goat (Capra aegagrus hircus) & 2 & $\begin{array}{l}\text { Slaughterhouse, } \\
\text { Bern, Switzerland }\end{array}$ & $12.5 \mathrm{ng} / \mathrm{mL}$ & $50 \mathrm{nM}$ & $0.48 \mu \mathrm{g} / \mathrm{mL}$ & $2.5 \mu \mathrm{M}$ \\
\hline Bactrian camel (Camelus bactrianus) & 1 & $\begin{array}{l}\text { Institute of Animal Pathology, } \\
\text { University of Bern, Switzerland }\end{array}$ & $5 \mathrm{ng} / \mathrm{mL}$ & $50 \mathrm{nM}$ & $0.072 \mu \mathrm{g} / \mathrm{mL}$ & NS \\
\hline Llama (Llama glama) & 2 & $\begin{array}{l}\text { Institute of Animal Pathology, } \\
\text { University of Bern, Switzerland }\end{array}$ & $5 \mathrm{ng} / \mathrm{mL}$ & $50 \mathrm{nM}$ & $0.072 \mu \mathrm{g} / \mathrm{mL}$ & NS \\
\hline Bat (Sturnira lilium) & 1 & $\begin{array}{l}\text { Costa Rica, (CIET-315-2013; } \\
\text { permit 1841/14) }\end{array}$ & $5 \mathrm{ng} / \mathrm{mL}$ & $50 \mathrm{nM}$ & $0.48 \mu \mathrm{g} / \mathrm{mL}$ & NS \\
\hline Bat (Carollia perspicillata) & 1 & $\begin{array}{l}\text { Costa Rica (CIET-315-2013; } \\
\text { permit 1841/14) }\end{array}$ & $5 \mathrm{ng} / \mathrm{mL}$ & $50 \mathrm{nM}$ & $0.48 \mu \mathrm{g} / \mathrm{mL}$ & NS \\
\hline
\end{tabular}

elsewhere (16). We monitored progeny virus release at 24-h intervals for $96 \mathrm{~h}$, through the application of $100 \mu \mathrm{L}$ of HBSS onto the apical surface and incubated 10 min before collection. We diluted collected apical washes 1:1 with virus transport medium and stored them at $-80^{\circ} \mathrm{C}$ for later analysis. After the collection of the apical washes, we exchanged the basolateral medium with fresh ALI medium. We repeated each experiment as 2 independent biologic replicates using AEC cultures established from either 1 or 2 biologic donors of each species depending on the availability of procured animal tissue (Table 1).

\section{Immunofluorescence Analysis}

We fixed virus-infected animal AEC cultures with $4 \%$ vol/vol neutral-buffered formalin at 96 hours postinfection (hpi) for SARS-CoV-2 or 48 hpi for IAV- or IDV-infected AEC cultures and processed them as described elsewhere (16). To detect SARS-CoV-2, we incubated fixed animal AEC cultures with a Rockland (https://rockland-inc.com) 200-401-A50 rabbit polyclonal antibody against SARS-CoV nucleocapsid protein, which has previously been shown to cross-react with SARS-CoV-2 (17). We used an Abcam (https:/ / www.abcam.com) ab128193 mouse antibody against IAV clone C43 nucleoprotein to detect IAV-infected cells and a custom-made rabbit polyclonal antibody against the nucleoprotein of influenza D/bovine/
Oklahoma/660/2013 strain (GenScript, https:// www.genscript.com) to detect IDV-infected cells. To visualize the distribution of ACE2 in the AEC cultures, we used Abcam ab15348 and Biorbyt (https:/ / www.biorbyt.com) orb582208 rabbit polyclonal antibodies against ACE2. We used Alexa Fluor 488 conjugated donkey anti-rabbit or anti-mouse IgG $(\mathrm{H}$ + L) as secondary antibodies. We used Alexa Fluor 647 -conjugated anti- $\beta$-tubulin (9F3) rabbit $\mathrm{mAb}$ (Thermo Fisher Scientific) to visualize cilia and Alexa Fluor 594 mouse anti-ZO1 1A12 monoclonal antibody to visualize tight junctions. We counterstained all samples using DAPI (4',6-diamidino-2-phenylindole; Thermo Fisher Scientific) to visualize the nuclei. We performed imaging using a Thermo Fisher EVOS FL Auto 2 imaging system equipped with a plan apochromat 40×/0.95 air objective; we processed images using Fiji software packages (https:/ / fiji.sc) (21) and assembled figures using the FigureJ plugin (https:/ / github.com/mutterer/figurej) (22). We adjusted brightness and contrast of images to be identical to their corresponding controls.

\section{Quantitative Real-Time Reverse Transcription PCR}

We extracted viral RNA from $100 \mu \mathrm{L}$ of 1:1 diluted apical wash using the NucleoMag VET (MachereyNagel AG, https://www.mn-net.com), according to the manufacturer's guidelines, on a Kingfisher Flex 
purification system (Thermo Fisher Scientific). We amplified $2 \mu \mathrm{L}$ of extracted RNA using TaqMan Fast Virus 1-Step Master Mix (Thermo Fisher Scientific) according to the manufacturer's protocol. We used a forward primer, adapted from primers described elsewhere (23): 5'-ACAGGTACGTTAATAGTTAATAGCGTACTTCT-3', reverse 5' - ACAATATTGCAGCAGTACGCACA-3', and probe 5'-FAM-ATCCTTACTGCGCTTCGA-MGB-Q530-3'(Microsynth,https://www. microsynth.ch), targeting the envelope gene of SARSCoV-2 (GenBank accession no. MN908947.3). As a positive control, we included a serial dilution of in vitro-transcribed RNA containing regions of the RNA-dependent RNA polymerase, envelope, and $\mathrm{N}$ genes derived from a SARS-CoV-2 synthetic construct (GenBank accession no. MT108784) to determine the genome copy number. We performed measurements and analysis using an Applied Biosystems ABI7500 instrument and associated software package (Thermo Fisher Scientific).

\section{Titration of SARS-CoV-2 in the Apical Washes}

To quantify SARS-CoV-2, we titrated apical washes by plaque assay on Vero E6 cells. In brief, we seeded $1 \times 10^{5}$ cells/well in 24-well plates $1 \mathrm{~d}$ before titration and inoculated them with 10-fold serial dilutions of virus solutions. We removed inoculums $1 \mathrm{hpi}$ and replaced them with overlay medium consisting of Dulbecco Modified Eagle Medium supplemented with 1.2\% Avicel (DuPont, https:/ / www.pharma.dupont. com), 10\% heat-inactivated fetal bovine serum, 100 $\mu \mathrm{g} / \mathrm{mL}$ streptomycin, and $100 \mathrm{IU} / \mathrm{mL}$ penicillin. We incubated cells at $37^{\circ} \mathrm{C}$ with $5 \% \mathrm{CO}_{2}$ for $48 \mathrm{~h}$ and fixed them with $4 \%$ vol/vol neutral buffered formalin before staining with crystal violet (24).

\section{ACE2 Homology Analysis}

To analyze ACE2 homology among different species, we retrieved the available ACE2 protein sequences for humans (GenBank accession no. NM_001371415.1), rhesus macaques (accession no. NM_001135696.1), cats (accession no. XM_023248796.1), ferrets (accession no. NM_001310190.1), dogs (accession no. NM_001165260.1), rabbits (accession no. XM_002719845.3), pigs (accession no. NM_001123070.1), cattle (accession no. XM_005228428.4), goats (accession no. NM_001290107.1), and Bactrian camels (accession no. XM_010968001.1). We acquired the ACE2 sequences for Carollia perspicillata bats from a study of SARS-CoV and SARS-CoV-2 infection among bats (25). We obtained the corresponding ACE2 sequences for llamas and Sturnira lilium bats (accession nos. MW863647 and MW863648) by reverse transcription PCR amplification of ACE2 mRNA, as described elsewhere (26). We performed sequence analysis and protein alignment using the ClustalW (https://www.genome.jp/tools-bin/ clustalw) plugin in Geneious Prime (https://www. geneious.com) with the default settings. We selected ACE2 protein residues interacting with SARS-CoV-2 RBM based on previously described critical ACE2 residues interacting with SARS-CoV-2 receptor binding domains $(27,28)$.

\section{Whole-Genome Sequencing Using Oxford Nanopore MinION}

We performed sequencing on viral RNA isolated from SARS-CoV-2 stock and the 96 hpi apical washes of SARS-CoV-2-infected monkey and cat AEC cultures according to the ARTIC platform nCoV19 protocols $(29,30)$. We used the version 2 protocol as a basis for the reverse transcription and tiled multiplex PCR reaction using the ARTIC nCoV-2019 V3 primer pool (Appendix 1, https://wwwnc.cdc.gov/EID/ article/27/7/20-4660-App1.xlsx), but we used the version 3 protocol for the downstream library preparation. We generated sequencing libraries using the EXP-NBD196 Native Barcoding Expansion 96 kit (Oxford Nanopore Technologies, https://nanoporetech. com) and sequenced on an Oxford Nanopore Technologies MinION R9.4.1 flow cell for $48 \mathrm{~h}$, according to the manufacturer's instructions. We used Oxford Nanopore MinION software version 20.06.4 to perform data acquisition and real-time high-accuracy basecalling. We performed demultiplexing and read filtering according to the ARTIC platform nCoV19 pipeline (https://artic.network/ncov-2019) and the experimental Medaka pipeline (https://community. artic.network/t/medaka-longshot-pipeline/107) to perform consensus calling. We aligned and further analyzed consensus sequences in Geneious 11.1.5 using SARS-CoV-2/Wuhan-Hu-1 (GenBank accession no. MN908947.3) as the reference sequence.

\section{Results}

To evaluate the susceptibility of a diverse set of animal species to SARS-CoV-2 infection, we infected a total of 12 different well-differentiated mammal AEC culture models and monitored the viral replication kinetics at both $33^{\circ} \mathrm{C}$ and $37^{\circ} \mathrm{C}$. Quantification of the viral RNA load at both temperatures showed a progressive 4-log fold increase in viral RNA load at 72 and 96 hpi in rhesus macaque and cat AEC cultures. In contrast, for the remaining animal AEC cultures we detected either a continuous or declining level of viral RNA load throughout the entire time course (Figure 1, panels A, B; Appendix 2, https:/ / wwwnc.cdc. gov/EID/article/27/7/20-4660-App2.pdf, Figure 1, 

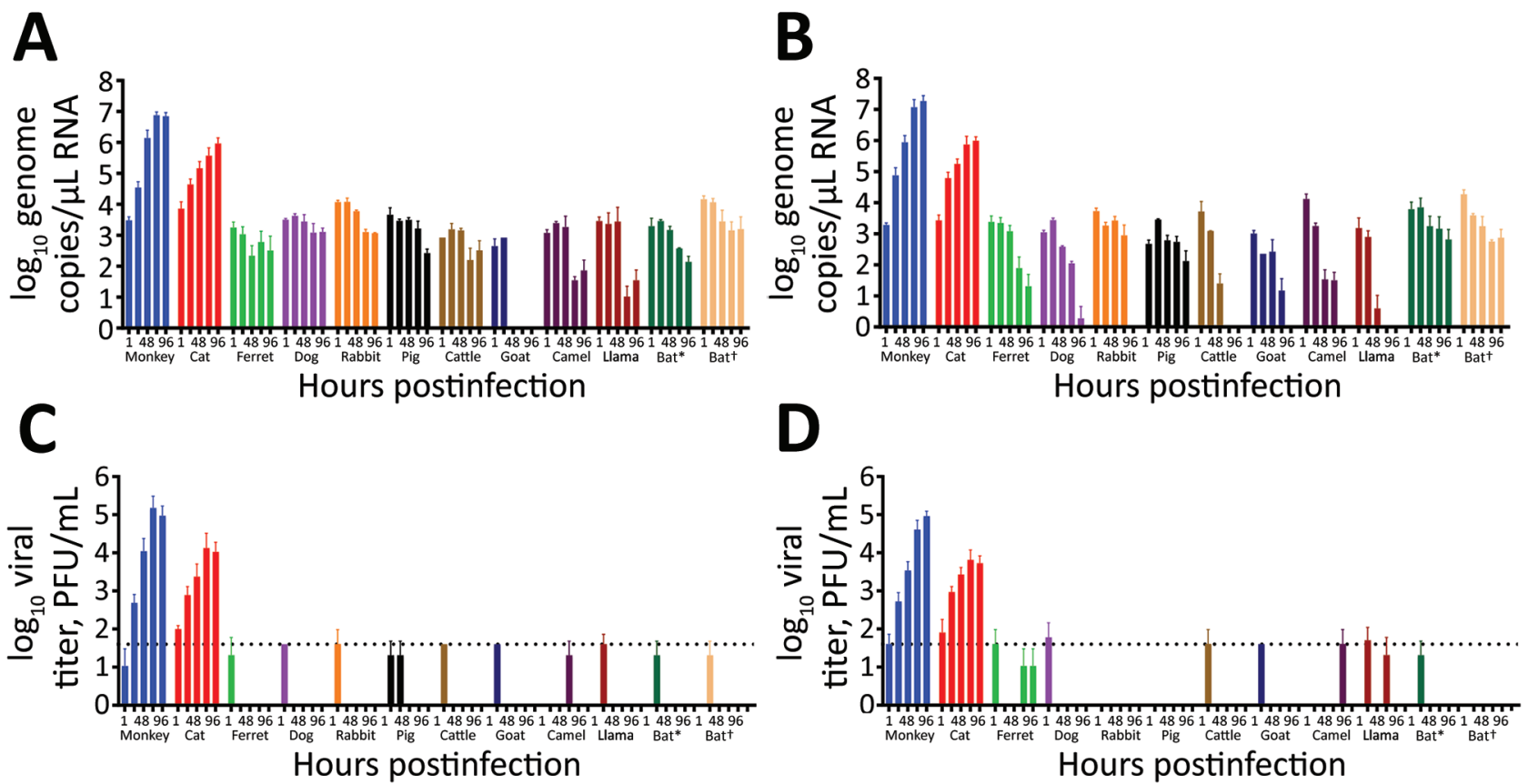

Figure 1. Severe acute respiratory syndrome coronavirus 2 replication kinetics in diverse mammal species. We inoculated welldifferentiated animal airway epithelial cell cultures derived from the tracheobronchial epithelial cells with 30.000 PFU of severe acute respiratory syndrome coronavirus 2 at either $33^{\circ} \mathrm{C}$ (panels $\mathrm{A}, \mathrm{C}$ ) or $37^{\circ} \mathrm{C}$ (panels $\mathrm{B}, \mathrm{D}$ ). We removed inoculated virus at 1 hour postinfection and washed the apical side 3 times. We further incubated cultures for $96 \mathrm{~h}$. At the indicated time postinfection, we assessed apical virus release by quantitative reverse transcription PCR targeting the $\mathrm{E}$ gene (panels A, B) and plaque titration assays on Vero E6 cells (panels C, D). Error bars represent the average of 2 independent biologic replicates using airway epithelial cell cultures established from 1 or 2 biologic donors. The dotted lines on panels $C$ and $D$ indicate the detection limit of the assay. ${ }^{*}$ Sturnira lilium bat; †Carollia perspicillata bat.

panels B, C). Because molecular assays cannot discern between infectious and noninfectious viruses, we also performed viral titration assays with the corresponding apical washes (31). This corroborated our previous finding that only AEC cultures from rhesus macaques and cats displayed a progressive increase in viral SARS-CoV-2 titers over time, and we detected no sustained productive virus infection above the detectable threshold beyond 24 hpi in most species (Figure 1, panels C, D; Appendix 2 Figure 1, panels D, E). The viral titers we observed in the rhesus macaque and cat AEC cultures were comparable to those we previously observed in human AEC cultures, where we also observed a 4-log fold rise in progeny-released virus in the apical side (17). Although ferrets have previously been shown to be susceptible to SARSCoV-2, we observed no viral replication in AEC cultures derived from the tracheobronchial regions of ferrets. Instead, we detected only low levels of SARS$\mathrm{CoV}-2$ viral titers at 72 and $96 \mathrm{hpi}$ at $37^{\circ} \mathrm{C}$, in agreement with findings from in vivo studies in ferrets showing a dose-dependent and limited SARS-CoV-2 infection restricted to the upper respiratory tract (32$34)$. We further analyzed SARS-CoV-2 infection in the animal AEC cultures by staining for SARS-CoV-2 nucleocapsid protein on formalin-fixed AEC cultures to visualize intracellular presence of the virus. This process revealed SARS-CoV-2 antigen-positive cells in rhesus macaque and cat AEC cultures at 96 hpi, but no SARS-CoV-2 antigen-positive cells were observed in the other animal AEC cultures, including those of ferrets (Figure 2; Appendix 2 Figure 1, panel A). This further confirmed that only monkey and cat AEC support efficient replication of SARS-CoV-2 among the animals we studied.

Because productive progeny virus production was only observed in the well-differentiated tracheobronchial epithelial cell cultures from rhesus macaques and cats, we wondered whether this was because of incompatibility with the cellular receptor used by SARS-CoV-2 for cellular entry $(27,35)$. To assess whether this corresponds to the amino acid sequence conservation of RBM in ACE2, we performed in silico analysis on the ACE2 protein sequences of the species included in this study $(27,28)$. This process revealed that the amino acid identity of the ACE2 $\mathrm{RBM}$ regions interacting with the receptor-binding domain of SARS-CoV-2 in humans were more similar 
to those in rhesus macaques and cats than in other species (Appendix 2 Figure 2, panel A).

Apart from receptor compatibility as a limiting factor for virus infection, it has been demonstrated previously that partially differentiated AEC cultures are poorly permissive to respiratory virus infection (36). To investigate whether the lack of replication in ferret cells, for example, was not caused by poor differentiation of our cell cultures, we validated the AEC cultures by infecting culture samples with the
2009 pandemic IAV A/Hamburg/4/2009 and ruminant-associated IAV D/bovine/Oklahoma/660/2013 strains. Both viruses are members of Orthomyxoviridae and are known to have a broad host spectrum, including ferrets (13-15,37). We inoculated the AEC cultures from 12 different species (rhesus macaque, cat, ferret, dog, rabbit, pig, cattle, goat, llama, camel, and 2 neotropical bats) with $10.000 \mathrm{TCID}_{50}$ of either IAV or IDV and incubated them at either $33^{\circ} \mathrm{C}$ or $37^{\circ} \mathrm{C}$. At $48 \mathrm{hpi}$, we fixed the AEC cultures and processed them by
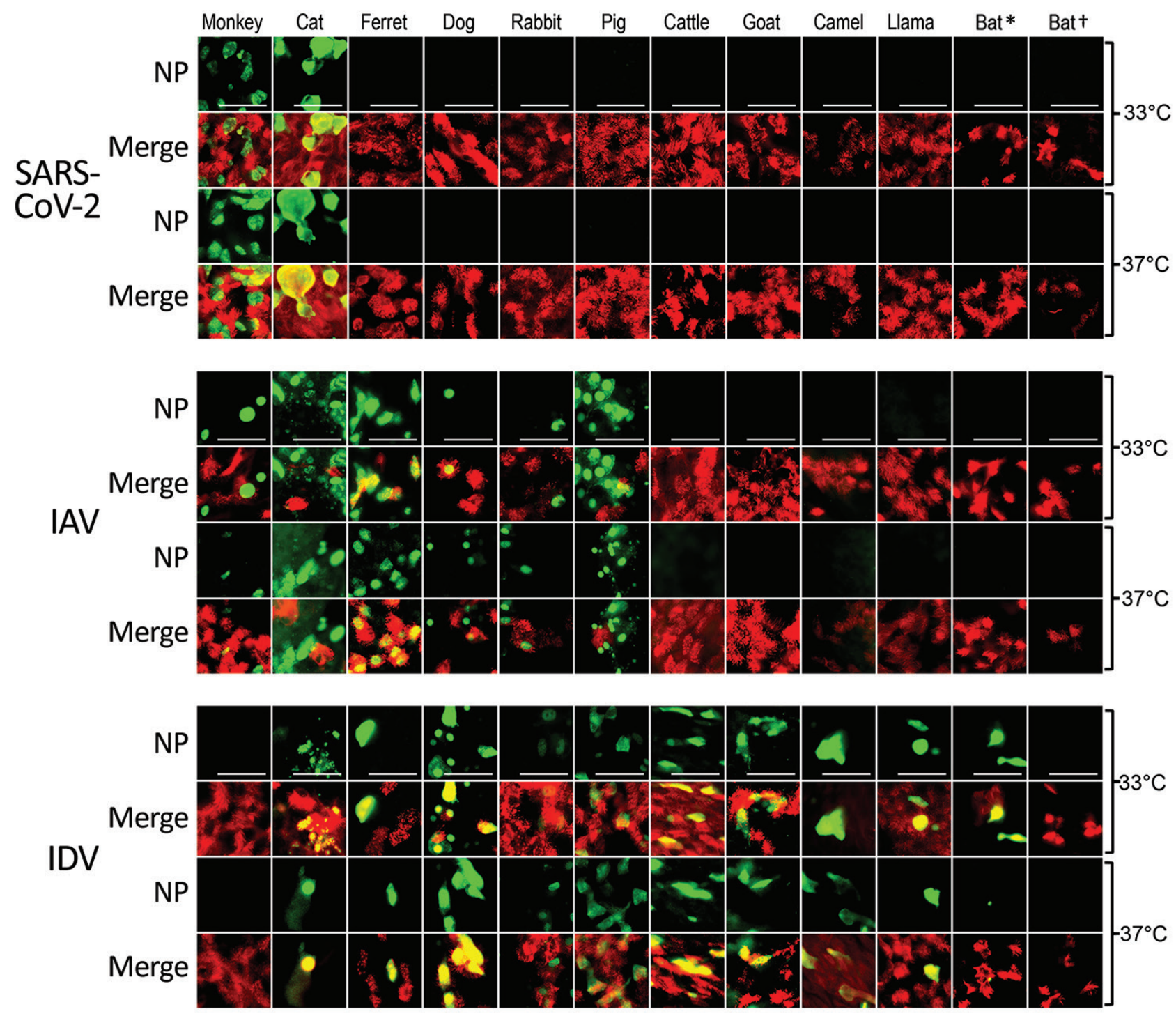

Figure 2. Tropisms of SARS-CoV-2, IAV, and IDV in infected airway epithelial cell cultures from diverse mammal species. We inoculated well-differentiated animal airway epithelial cell cultures with either 30.000 PFU of SARS-CoV-2 (SARS-CoV-2/München-1.1/2020/929), $10.00050 \%$ tissue culture infective dose of IAV/Hamburg/4/2009, or IDV (D/bovine/Oklahoma/660/2013). We incubated virus-infected airway epithelial cell cultures at $33^{\circ} \mathrm{C}$ or $37^{\circ} \mathrm{C}$ and formalin-fixed them at 96 hours postinfection (for SARS-CoV-2) or 48 hours postinfection (for influenza viruses). After fixation, we stained virus-infected cultures using antibodies against either SARS-CoV-2, IAV, or IDV NP (green), and $\beta$-tubulin (cilia, red). We acquired images using an EVOS FL Auto 2 Imaging System equipped with a 40x air objective. Scale bar indicates $50 \mu \mathrm{m}$. * Sturnira lilium bat; †Carollia perspicillata bat. IAV, influenza A virus; IDV, influenza D virus; NP, nucleocapsid protein; SARS-CoV-2, severe acute respiratory syndrome coronavirus 2. 


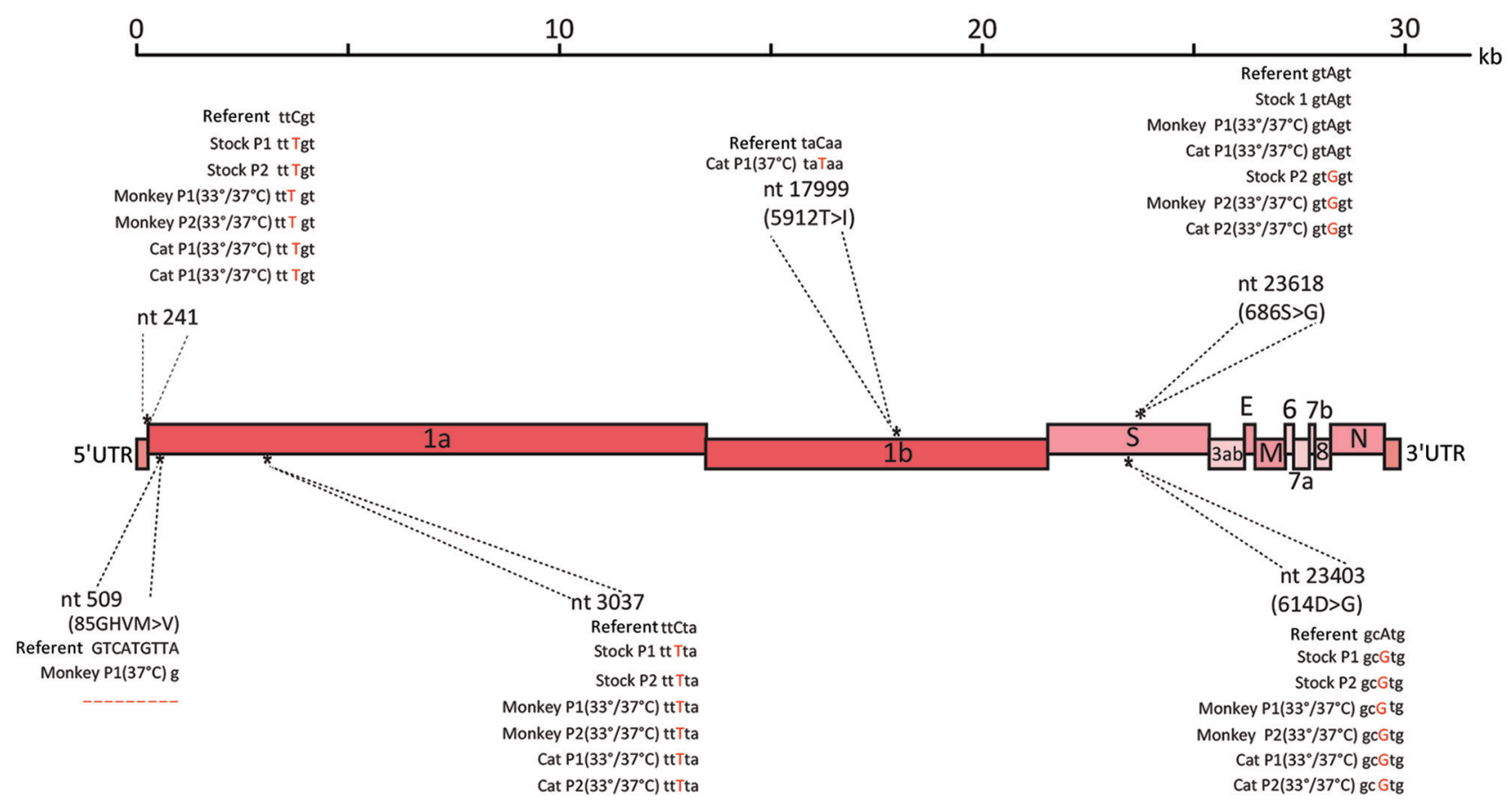

Figure 3. Whole-genome sequencing analysis using Nanopore sequencing technology (Oxford Nanopore Technologies, https:// nanoporetech.com). A graphical representation of variants found in the severe acute respiratory syndrome coronavirus 2 (SARS-CoV-2) stock $\mathrm{P} 1$ and $\mathrm{P} 2$, as well as the apical washes from SARS-CoV-2-infected monkey and cat airway epithelial cell cultures with either $\mathrm{P} 1$ or P2 stock $96 \mathrm{hpi}$ at $33^{\circ} \mathrm{C}$ or $37^{\circ} \mathrm{C}$. SARS-CoV-2/Wuhan-Hu-1 (GenBank accession no. MN908947.3) was used as the reference sequence. $P$, passage; UTR, untranslated region.

immunofluorescence assays. This analysis showed that, in contrast with SARS-CoV-2 testing results, IAV antigen-positive cells could be detected in AEC cultures from companion animals and from animals commonly used for testing, such as ferret, monkey, rabbit, and pigs (Figure 2; Appendix 2 Figure 1, panel A) (38). For IDV infections, we observed antigen-positive cells in all AEC models, except for rhesus macaques and 1 of the neotropical bat species, indicating that AEC cultures were all well-differentiated and susceptible to virus infection.

In the immunofluorescence analysis, we also incorporated an antibody against $\beta$-tubulin marker to discern ciliated and nonciliated cell populations. For both rhesus macaques and cats, SARS-CoV-2 antigenpositive cells predominantly overlapped with the nonciliated cell populations, at either incubation temperature. Using polyclonal antibodies against ACE2, we found that the cellular receptor expression in rhesus macaques and cats predominantly overlapped with SARS-CoV-2 cell tropism, similar to ACE2 distribution in human AEC cultures (Appendix 2 Figure 2, panel B) (17). Unfortunately, because of limited availability of well-differentiated AEC cultures, we could not assess the ACE2 expression in goat, cattle, and rabbit AEC cultures. Nevertheless, for most species, includ- ing ferrets, that did not support efficient replication of SARS-CoV-2, we observed that ACE2 was expressed on the cell surface (Appendix 2 Figure 2, panel B). This finding suggests that ACE2 expression alone does not per se confer permissiveness to SARS-CoV-2.

It has previously been shown that SARS-CoV-2 can undergo rapid genetic changes in vitro (39). Because we observed efficient replication in rhesus macaque and cat AEC cultures, we assessed whether any mutations suggestive of viral adaptation had occurred. We performed whole-genome sequencing (Oxford Nanopore Technologies) on the viral inoculum used, as well as on the progeny viruses collected from the rhesus macaque and cat AEC cultures incubated at $33^{\circ} \mathrm{C}$ or $37^{\circ} \mathrm{C}$ after 1 passage, at $96 \mathrm{hpi}$. This inoculum was from either passage 1 or passage 2 virus stocks from the SARS-CoV-2/München-1.1/2020/929 isolate we had received. In the viral sequences in the 96 hpi samples from virus-infected rhesus macaque and cat AEC cultures, we observed no obvious signs of nucleotide transitions that led to nonsynonymous mutations compared to the respective inoculums (Figure 3), regardless of temperature and animal species. This finding highlights that the currently circulating SARS-CoV-2 D614G variant can productively infect rhesus macaque and cat AEC. 


\section{Discussion}

Our study used an in vitro AEC culture repository composed of various domestic and wildlife animal species to assess the spectrum of potential intermediate and spillback host reservoirs for SARS-CoV-2. Inoculation of AEC cultures from rhesus macaque, cat, ferret, dog, rabbit, pig, cattle, goat, llama, camel, and 2 neotropical bat species with SARS-CoV-2 revealed that tracheobronchial cells only from rhesus macaque monkeys and cats supported efficient replication of SARS$\mathrm{CoV}-2$. Whole-genome sequencing indicated that the currently circulating SARS-CoV-2 D614G variant can efficiently infect rhesus macaque and cat AEC. Our data highlight that these 2 animals are potential models for evaluating therapeutic mitigation strategies for circulating viral variants. Our findings, in conjunction with information from previously documented spillover events, indicate that close surveillance of these animals and closely related species, whether in the wild, captivity, or households, is warranted.

To date, there have been several reports published evaluating the suitability of animal models, including cats, rhesus macaques, dogs, pigs, rabbit and ferrets, for testing SARS-CoV-2 infection (32,33,40-43). We observed that SARS-CoV-2 did not efficiently replicate in tracheobronchial AEC derived from rabbits and ferrets, although ferrets are used as an animal model for SARS$\mathrm{CoV}-2$. This finding may be because viral infections in rabbits and ferrets are mainly restricted to the nasal conchae, are dose-dependent and, in addition, the origin of the cells used as input for the AEC cultures may not recapitulate the cells of the nasal mucosa $(34,40,42,43)$. Differences exist in cellular composition and host determinant expression levels along proximal and distal regions of the respiratory tract (44). In addition, SARSCoV-2 might use a different cellular receptor in ferrets, although ACE2 could be detected on the cell surface (Appendix 2 Figure 2, panel B) (45). Therefore, it would be of interest to complement our current repository with AEC cultures from different anatomic regions of animals such as rabbits and ferrets and to evaluate whether ACE2 is the cellular receptor employed by SARS-CoV-2 in these various animal species.

It has been proposed that SARS-CoV-2 spillover into humans, as with SARS-CoV, originally occurred from bats, either directly or through an intermediate reservoir $(3,46)$. With $>1,400$ bat species comprising $>20 \%$ of all mammal species, we restricted our experiments with SARS-CoV-2 to our established AEC cultures from the 2 neotropical bat species C. perspicillata and S. lilium (M. Gultom et al., unpub. data). We showed that these 2 neotropical bats express ACE2 but are not susceptible to SARS-CoV-2, suggesting that they are not likely reservoir hosts for SARS-CoV-2 despite the detection of other coronaviruses and presumptive ACE2 receptor usage by SARS-CoV-2 in closely related bat species $(25,47)$. In fact, a 2020 study described susceptibility to SARS-CoV-2 infection in fruit bats (Rousettus aegyptiacus) (33). Future research should therefore include AEC cultures from this bat species, as well as from horseshoe bat species (genus Rhinolophus), which have previously been characterized as reservoir hosts for viruses with a close genetic relationship to the coronavirus associated with the 2003 SARS outbreak $(33,46)$. In summary, our results highlight that in vitro well-differentiated animal AEC culture models can be used as an alternative to traditional animal experimentation models to evaluate and provide insight into the host spectrum of SARS-CoV-2.

\section{Acknowledgments}

We gratefully thank Lia van der Hoek for critical reading of the manuscript and helpful discussions. Moreover, we would like to thank Doreen Muth, Marcel Müller, and Christian Drosten for providing us Vero E6 cells and the SARS-CoV-2/München-1.1/2020/929 virus isolate; Martin Schwemmle for providing us the influenza A/Hamburg/4/2009 (H1N1pdm09) virus reverse genetic system; and Feng Li for sharing the influenza D/bovine/ Oklahoma/660/2013 virus isolate.

This study was supported by research grants from the European Commission (Marie Sklodowska-Curie Innovative Training Network HONOURS; grant agreement no. 721367), the Swiss National Science Foundation (SNSF grants 310030_179260,31CA30_196062, and 31CA30_196644), the Federal Food Safety and Veterinary Office (FSVO grant 1.20.02), the German Research Foundation (DFG, SFB 1021, project B01), and Federal Ministry of Education and Research (BMBF; grant RAPID, \#01KI1723A).

\section{About the Author}

Ms. Gultom is a PhD student at the University of Bern, Bern, Switzerland. Her research interest lies with the establishment of primary airway epithelial cell cultures to study emerging respiratory viruses.

\section{References}

1. Drosten C, Günther S, Preiser W, van der Werf S, Brodt H-R, Becker $S$, et al. Identification of a novel coronavirus in patients with severe acute respiratory syndrome. N Engl J Med. 2003;348:1967-76. https://doi.org/10.1056/ NEJMoa030747

2. Zaki AM, van Boheemen S, Bestebroer TM, Osterhaus ADME, Fouchier RAM. Isolation of a novel coronavirus from a man with pneumonia in Saudi Arabia. N Engl J Med. 2012; 367:1814-20. https://doi.org/10.1056/NEJMoa1211721 
3. Zhou P, Yang X-L, Wang X-G, Hu B, Zhang L, Zhang W, et al. A pneumonia outbreak associated with a new coronavirus of probable bat origin. Nature. 2020;579:270-3. https://doi.org/10.1038/s41586-020-2012-7

4. Li Q, Guan X, Wu P, Wang X, Zhou L, Tong Y, et al. Early transmission dynamics in Wuhan, China, of novel coronavirus-infected pneumonia. N Engl J Med. 2020;382:1199-207. https://doi.org/10.1056/NEJMoa2001316

5. Oreshkova N, Molenaar RJ, Vreman S, Harders F, Oude Munnink BB, Hakze-van der Honing RW, et al. SARS-CoV-2 infection in farmed minks, the Netherlands, April and May 2020. Euro Surveill. 2020;25:2001005. https:/ / doi.org/10.2807/1560-7917.ES.2020.25.23.2001005

6. Leroy EM, Ar Gouilh M, Brugère-Picoux J. The risk of SARS-CoV-2 transmission to pets and other wild and domestic animals strongly mandates a one-health strategy to control the COVID-19 pandemic. One Health. 2020;10:100133. https://doi.org/10.1016/j.onehlt.2020.100133

7. Segalés J, Puig M, Rodon J, Avila-Nieto C, Carrillo J, Cantero G, et al. Detection of SARS-CoV-2 in a cat owned by a COVID-19-affected patient in Spain. Proc Natl Acad Sci U S A. 2020;117:24790-3. https://doi.org/10.1073/pnas.2010817117

8. Liu Z, Xiao X, Wei X, Li J, Yang J, Tan H, et al. Composition and divergence of coronavirus spike proteins and host ACE2 receptors predict potential intermediate hosts of SARS-CoV-2. J Med Virol. 2020;92:595-601. https:/ / doi.org/10.1002/jmv.25726

9. Lam SD, Bordin N, Waman VP, Scholes HM, Ashford P, Sen N, et al. SARS-CoV-2 spike protein predicted to form complexes with host receptor protein orthologues from a broad range of mammals. Sci Rep. 2020;10:16471. https://doi.org/10.1038/s41598-020-71936-5

10. Vergara-Alert J, van den Brand JMA, Widagdo W, Muñoz M V, Raj S, Schipper D, et al. Livestock susceptibility to infection with Middle East respiratory syndrome coronavirus. Emerg Infect Dis. 2017;23:232-40. https:/ / doi.org/ 10.3201/eid2302.161239

11. Kalthoff D, Grund C, Harder TC, Lange E, Vahlenkamp TW, Mettenleiter TC, et al. Limited susceptibility of chickens, turkeys, and mice to pandemic (H1N1) 2009 virus. Emerg Infect Dis. 2010;16:703-5. https:/ / doi.org/10.3201/ eid1604.091491

12. Weingartl HM, Copps J, Drebot MA, Marszal P, Smith G, Gren J, et al. Susceptibility of pigs and chickens to SARS coronavirus. Emerg Infect Dis. 2004;10:179-84. https:/ / doi.org/10.3201/eid1002.030677

13. O'Donnell CD, Subbarao K. The contribution of animal models to the understanding of the host range and virulence of influenza A viruses. Microbes Infect. 2011;13:502-15. https:/ / doi.org/10.1016/j.micinf.2011.01.014

14. Parrish CR, Murcia PR, Holmes EC. Influenza virus reservoirs and intermediate hosts: dogs, horses, and new possibilities for influenza virus exposure of humans. J Virol. 2015;89:2990-4. https://doi.org/10.1128/JVI.03146-14

15. Asha K, Kumar B. Emerging influenza D virus threat: what we know so far! J Clin Med. 2019;8:192. https:/ / doi.org/ 10.3390/jcm8020192

16. Gultom M, Laloli L, Dijkman R. Well-differentiated primary mammalian airway epithelial cell cultures In: Maier HJ, Bickerton E, editors. Coronaviruses: methods and protocols. New York: Springer; 2020.

17. V'kovski P, Gultom M, Kelly JN, Steiner S, Russeil J, Mangeat B, et al. Disparate temperature-dependent virushost dynamics for SARS-CoV-2 and SARS-CoV in the human respiratory epithelium. PLoS Biol. 2021;19:e3001158. https:/ / doi.org/10.1371/journal.pbio.3001158
18. Edinger TO, Pohl MO, Yángüez E, Stertz S. Cathepsin W is required for escape of influenza A virus from late endosomes. MBio. 2015;6:e00297. https:/ / doi.org/10.1128/mBio.00297-15

19. Hierholzer JC, Killington RA, Stokes A. Preparation of antigens. Mahy BWJ, Kangro HO, editors. Virology methods manual. London: Academic Press. 1996. p. 25-46.

20. Holwerda M, Kelly J, Laloli L, Stürmer I, Portmann J, Stalder H, et al. Determining the replication kinetics and cellular tropism of influenza D virus on primary welldifferentiated human airway epithelial cells. Viruses. 2019;11:377. https:/ / doi.org/10.3390/v11040377

21. Schindelin J, Arganda-Carreras I, Frise E, Kaynig V, Longair M, Pietzsch T, et al. Fiji: an open-source platform for biological-image analysis. Nat Methods. 2012;9:676-82. https://doi.org/10.1038/nmeth.2019

22. Mutterer J, Zinck E. Quick-and-clean article figures with FigureJ. J Microsc. 2013;252:89-91. https:/ / doi.org/10.1111/ jmi.12069

23. Corman VM, Landt O, Kaiser M, Molenkamp R, Meijer A, Chu DKW, et al. Detection of 2019 novel coronavirus (2019$\mathrm{nCoV}$ ) by real-time RT-PCR. Euro Surveill. 2020;25:2000045. https://doi.org/10.2807/1560-7917.ES.2020.25.3.2000045

24. Jonsdottir HR, Dijkman R. Characterization of human coronaviruses on well-differentiated human airway epithelial cell cultures. In: Maier HJ, Bickerton E, Britton P, editors. Coronaviruses: methods and protocols. New York: Springer; 2015. p. 73-87.

25. Yan H, Jiao H, Liu Q, Zhang Z, Xiong Q, Wang B-J, et al. ACE2 receptor usage reveals variation in susceptibility to SARS-CoV and SARS-CoV-2 infection among bat species. Nat Ecol Evol. 2021;5:600-8. https:/ / doi.org/10.1038/ s41559-021-01407-1

26. Hou Y, Peng C, Yu M, Li Y, Han Z, Li F, et al. Angiotensinconverting enzyme 2 (ACE2) proteins of different bat species confer variable susceptibility to SARS-CoV entry. Arch Virol. 2010;155:1563-9. https:/ / doi.org/10.1007/s00705-010-0729-6

27. Lan J, Ge J, Yu J, Shan S, Zhou H, Fan S, et al. Structure of the SARS-CoV-2 spike receptor-binding domain bound to the ACE2 receptor. Nature. 2020;581:215-20. https:/ / doi.org/ 10.1038/s41586-020-2180-5

28. Wang Q, Zhang Y, Wu L, Niu S, Song C, Zhang Z, et al. Structural and functional basis of SARS-CoV-2 entry by using human ACE2. Cell. 2020;181:894-904.e9. https:/ / doi.org/10.1016/j.cell.2020.03.045

29. Quick J. nCoV-2019 sequencing protocol v2 (GunIt). 2020 [cited 2020 Sep 28]. https:/ / dx.doi.org/10.17504/protocols. io.bdp7i5rn

30. Quick J. nCoV-2019 sequencing protocol v3 (LoCost). 2020 [cited 2020 Sep 28]. https:/ / protocols.io/view/ncov-2019sequencing-protocol-v3-locost-bh42j8ye

31. Bullard J, Dust K, Funk D, Strong JE, Alexander D, Garnett L, et al. Predicting infectious severe acute respiratory syndrome coronavirus 2 from diagnostic samples. Clin Infect Dis. 2020;71:2663-6. https://doi.org/10.1093/cid/ciaa638

32. Shi J, Wen Z, Zhong G, Yang H, Wang C, Huang B, et al. Susceptibility of ferrets, cats, dogs, and other domesticated animals to SARS-coronavirus 2. Science. 2020;368:1016-20. https://doi.org/10.1126/science.abb7015

33. Schlottau K, Rissmann M, Graaf A, Schön J, Sehl J, Wylezich C, et al. SARS-CoV-2 in fruit bats, ferrets, pigs, and chickens: an experimental transmission study. Lancet Microbe. 2020;1:e218-25. https:/ / doi.org/10.1016/ S2666-5247(20)30089-6

34. Ryan KA, Bewley KR, Fotheringham SA, Slack GS, Brown P, Hall Y, et al. Dose-dependent response to infection with SARS-CoV-2 in the ferret model and evidence 
of protective immunity. Nat Commun. 2021;12:81.

https://doi.org/10.1038/s41467-020-20439-y

35. Matsuyama S, Nagata N, Shirato K, Kawase M, Takeda M, Taguchi F. Efficient activation of the severe acute respiratory syndrome coronavirus spike protein by the transmembrane protease TMPRSS2. J Virol. 2010;84:12658-64. https://doi.org/10.1128/JVI.01542-10

36. Zhang L, Peeples ME, Boucher RC, Collins PL, Pickles RJ. Respiratory syncytial virus infection of human airway epithelial cells is polarized, specific to ciliated cells, and without obvious cytopathology. J Virol. 2002;76:5654-66. https:// doi.org/10.1128/JVI.76.11.5654-5666.2002

37. Hause BM, Ducatez M, Collin EA, Ran Z, Liu R, Sheng Z, et al. Isolation of a novel swine influenza virus from Oklahoma in 2011 which is distantly related to human influenza C viruses. PLoS Pathog. 2013;9:e1003176. https:/ / doi.org/10.1371/journal.ppat.1003176

38. Wu NH, Yang W, Beineke A, Dijkman R, Matrosovich M, Baumgärtner $W$, et al. The differentiated airway epithelium infected by influenza viruses maintains the barrier function despite a dramatic loss of ciliated cells. Sci Rep. 2016;6:39668. https://doi.org/10.1038/srep39668

39. Ogando NS, Dalebout TJ, Zevenhoven-Dobbe JC, Limpens RWAL, van der Meer Y, Caly L, et al. SARScoronavirus-2 replication in Vero E6 cells: replication kinetics, rapid adaptation and cytopathology. J Gen Virol. 2020;101:925-40. https:/ / doi.org/10.1099/jgv.0.001453

40. Kim Y-I, Kim S-G, Kim S-M, Kim E-H, Park S-J, Yu K-M, et al. Infection and rapid transmission of SARS-CoV-2 in ferrets. Cell Host Microbe. 2020;27:704-709.e2. https://doi.org/10.1016/j.chom.2020.03.023

41. Munster VJ, Feldmann F, Williamson BN, van Doremalen N, Pérez-Pérez L, Schulz J, et al. Respiratory disease in rhesus macaques inoculated with SARS-CoV-2. Nature. 2020;585:268-72. https://doi.org/10.1038/s41586-020-2324-7

42. Richard M, Kok A, de Meulder D, Bestebroer TM, Lamers MM, Okba NMA, et al. SARS-CoV-2 is transmitted via contact and via the air between ferrets. Nat Commun. 2020;11:3496. https:// doi.org/10.1038/s41467-020-17367-2

43. Mykytyn AZ, Lamers MM, Okba NMA, Breugem TI, Schipper D, van den Doel PB, et al. Susceptibility of rabbits to SARS-CoV-2. Emerg Microbes Infect. 2021;10:1-7. https:/ / doi.org/10.1080/22221751.2020.1868951

44. Hou YJ, Okuda K, Edwards CE, Martinez DR, Asakura T, Dinnon KH III, et al. SARS-CoV-2 reverse genetics reveals a variable infection gradient in the respiratory tract. Cell. 2020;182:429-446.e14. https:/ / doi.org/10.1016/ j.cell.2020.05.042

45. Gramberg T, Hofmann H, Möller P, Lalor PF, Marzi A, Geier M, et al. LSECtin interacts with filovirus glycoproteins and the spike protein of SARS coronavirus. Virology. 2005;340:224-36. https://doi.org/10.1016/ j.virol.2005.06.026

46. Li W, Shi Z, Yu M, Ren W, Smith C, Epstein JH, et al. Bats are natural reservoirs of SARS-like coronaviruses. Science. 2005;310:676-9. https://doi.org/10.1126/science.1118391

47. Góes LGB, Campos ACA, Carvalho C, Ambar G, Queiroz LH, Cruz-Neto AP, et al. Genetic diversity of bats coronaviruses in the Atlantic Forest hotspot biome, Brazil. Infect Genet Evol. 2016;44:510-3. https:// doi.org/10.1016/ j.meegid.2016.07.034

Address for correspondence: Ronald Dijkman, Institute for Infectious Diseases, University of Bern, Friedbühlstrasse 51, 3001 Bern, Switzerland; email: ronald.dijkman@ifik.unibe.ch

\section{EID Podcast Oral HPV Infection in Children, Finland}

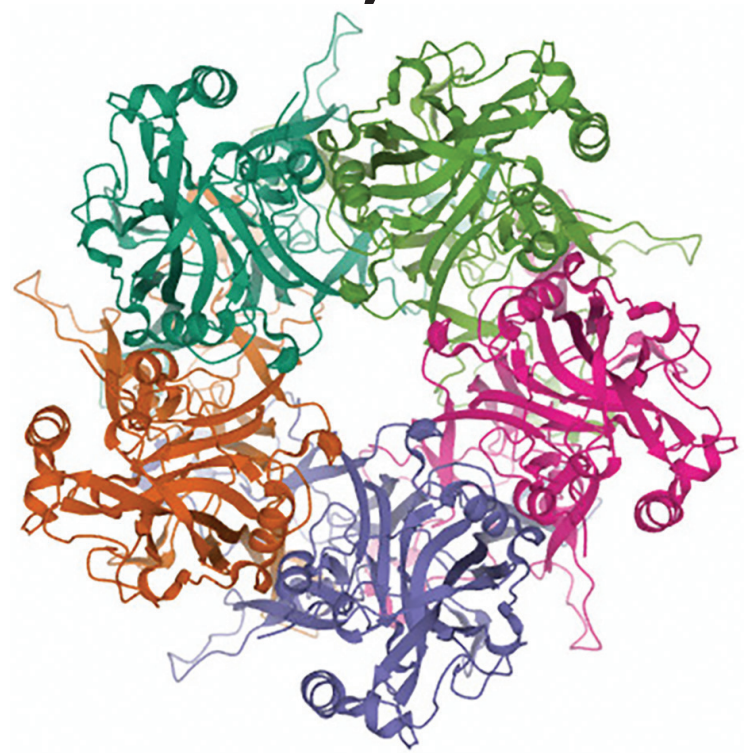

Image credit: Wikimedia Commons, Deposition authors: Bishop, B., Dasgupta, J., Chen, X.S.; http://www.rcsb.org/structure/2r5k

Human papillomavirus (HPV) is usually thought of as a sexually transmitted infection.

However, HPV also can spread through other forms of contact. New research indicates that it might even be common for mothers to transmit the virus to their children before, during, and after birth.

In this EID podcast, Dr. Stina Syrjänen, a professor and chairman emerita at the University of Turku and chief physician in the Department of Pathology at Turku University Hospital in Finland, describes her findings on nonsexual transmission of HPV among young children and families.

Visit our website to listen: https://go.usa.gov/xHKGj EMERGING INFECTIOUS DISEASES ${ }^{\circ}$ 